\title{
Influencia de la comunicación técnica en la coordinación de la atención geriátrica durante la crisis del COVID-19 en la provincia de Lugo. Estudio prospectivo
}

\section{Influence of technical communication on the coordination of geriatric care during the COVID-19 crisis in the province of Lugo. Prospective study}

Laura Gamonal Gonzáleza, Laura García Tuñas ${ }^{b}$, Vanessa Álvarez Vidala, Romina Mouriz Corbellec, Mª $^{a}$ del Rocío Malfeito Jiméneza, José Caamaño Ponted

a Hospital de Día de Procesos, Servicio de Geriatría, Hospital Universitario Lucus Augusti, España

b Unidad de Terapia Ocupacional, Servicio de Gerontología Clínica, Complexo Terapéutico Xerontolóxico A Veiga, España

c Unidad de Psicología, Servicio de Gerontología Clínica, Complexo Terapéutico Xerontolóxico A Veiga, España

d Área de Ciencias de la Salud, Departamento de Trabajo Social Sanitario, Universidad Oberta de Cataluña, España

\section{Resumen}

Introducción: La pandemia producida por el coronavirus SARS-CoV-2 supone un gran reto sanitario con efectos económicos y sociales patentes. La salud de la población mundial peligra y las formas habituales de afrontar situaciones epidémicas son puestas en cuestión, lo que hace necesario un esfuerzo de coordinación en la atención a las personas mayores. Objetivo: Conocer la influencia que la comunicación técnica producida durante la crisis sanitaria generada a raíz del COVID-19 podrá ejercer sobre la coordinación de la atención geriátrica en la provincia de Lugo. Metodología: Estudio prospectivo Delphi empleando un cuestionario de doble circulación a cumplimentar por expertos en Geriatría y Gerontología de la provincia de Lugo constituídos en dos paneles. Resultados: $\mathrm{N}=26$ ( 20 mujeres, 6 hombres). Rango de edad: $25-63$ años. Las respuestas medias de ambos paneles se han aproximado y los rangos se han estrechado en la segunda circulación de la encuesta. Conclusión: Una estrategia de comunicación bidireccional entre los profesionales de la Geriatría y la Gerontología, basada en documentación técnica y científica, facilitará la coordinación entre niveles asistenciales y mejorará las expectativas de salud de las personas mayores en situaciones de crisis aunque también en la cronicidad.

Palabras clave: COVID-19; Vejez; Niveles asistenciales; Geriatría; Comunicación.

\section{Abstract}

Introduction: The pandemic caused by the SARS-CoV-2 coronavirus represents a major health challenge with obvious economic and social effects. The health of the world population is in danger and the usual ways of tackling epidemic situations are called into question, thus requiring an effort of coordination in the care of the elderly. Objective: To know the influence that the technical communication produced during the health crisis generated as a result of COVID-19 may exert on the coordination of geriatric care in the province of Lugo. Methodology: Prospective Delphi study using a double circulation questionnaire to be completed by experts in Geriatrics and Gerontology from Lugo province, consisting of two panels. Results: N = 26 (20 women, 6 men). Age range: 25 - 63 years. The average responses of both panels were approximated and the ranges narrowed in the second circulation of the survey. Conclusion: A two-way communication strategy between Geriatrics and Gerontology professionals, based on technical and scientific documentation, will facilitate coordination between healthcare levels and improve the health expectations of older people in crisis situations, but also in chronicity.

Key words: COVID-19; Old Age; Care Levels; Geriatrics; Communication. 


\section{Introducción}

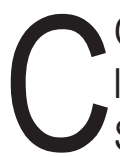

OVID-19 (Coronavirus Infectious Disease-19), la pandemia ocasionada por el coronavirus SARS-CoV-2 está suponiendo un enorme reto epidemiológico para el sistema sanitario además de constituir un drama social y económico de difícil proyección.

Las autoridades sanitarias de la República Popular China comunicaron el día 31 de diciembre diversos casos de neumonía de etiología desconocida en la ciudad de Wuhan, identificando posteriormente el agente causal, un nuevo coronavirus denominado SARS-CoV-2. En España, el primer paciente confirmado se comunicó el 31 de enero de 2020 mientras en Galicia lo fue el 4 de marzo de 2020. Poco más de 2 meses después de conocerse la casuística inicial de Wuhan, el director general de la Organización Mundial de la Salud, Dr. Tedros Adhanom Ghebreyesus, en la rueda de prensa sobre la COVID-19 celebrada el 11 de marzo de 2020 declaró la pandemia.

Lainfección poreste coronaviruscausamanifestaciones clínicas que se engloban en el término COVID-19 e incluyen diversos cuadros respiratorios, desde resfriado común hasta neumonía grave con síndrome de disnea, shock séptico y fallo sistémico, aunque la mayoría de los casos parecen cursar con cuadros leves, incluso, asintomáticos. La presentación clínica de la COVID-19 es heterogénea y su gravedad también lo es, siendo los pacientes frágiles por comorbilidad y los ancianos, más vulnerables y de peor pronóstico debido al proceso biológico del envejecimiento y a la disminución de la reserva funcional, lo que limita la respuesta inmune frente a la infección (Wang, Horby, Hayden \& Gao, 2020). Los estudios destacan que los síntomas prevalentes son la fiebre, la tos y la disnea, pueden aparecer también dolor faríngeo, rinorrea, astenia, anorexia, mialgias, cefalea, anosmia, diarrea y complicaciones cardiovasculares. Sin embargo el cuadro respiratorio más severo es la neumonía bilateral objetivable en las pruebas de imagen torácica. En las personas de edad anciana puede no presentarse fiebre o existir dificultades para discriminar la incidencia asociada de síntomas como la tos o la disnea pues frecuentemente existen patologías crónicas que las justifican dificultando el diagnóstico diferencial (Bonadad et al., 2020).

Lo cierto es que esa infección por coronavirus, desde China se ha extendido por los 5 continentes en forma pandémica con más de 3.100 .000 afectados entre los meses de enero y abril de 2020, y una incidencia especialmente relevante en países como Estados Unidos,
China y varios de la Unión Europea como Italia o España (UE= 1.441 .963 infectados, 136.359 fallecidos y 511.555 curados) finalizado el mes de abril de 2020 (Ministerio de Sanidad, Consumo y Bienestar Social [MSCBS], 2020).

La información a través de los medios de comunicación puede percibirse como abrumadora pues, prensa escrita, radio, televisión o internet han facilitado una amplísima cobertura a la población. Así, estadísticas de incidencia y prevalencia, índice de contagios y número básico de reproducción efectiva $(\mathrm{R} 0)$, personal sanitario infectado, pruebas de reacción en cadena de la polimerasa (PCR) efectuadas, número de fallecimientos, seguimientos domiciliarios, altas y otras se actualizan diariamente formando parte del lenguaje común y generando dispares debates, entre ellos el que cuestiona el modelo de atención a las personas mayores en instituciones geriátricas de perfil social por la especial incidencia del coronavirus en estos centros.

Sanitariamente, la situación global de la pandemia es crítica en cuanto a extensión y consecuencias y, en España, dos son los colectivos que parecen especialmente afectados, el personal sanitario (por su relevancia como garante de la salud de la población y sostén del sistema) y las personas mayores, de modo singular aquellas institucionalizadas con graves patologías pulmonares, cardiovasculares, renales y sistémicas (por su elevada morbimortalidad) aunque con diferente distribución según lugar de vivienda y área geográfica. De esta forma, a día 30 de abril de 2020, en España las estadísticas mostraban 241.310 infectados (positivos confirmados por PCR), 24.543 fallecidos y 112.050 curados. Muy considerable es el número de profesionales de la salud afectados, más de 35.000 , supone el $21,4 \%$ de los casos notificados, siendo significativamente mayor este porcentaje entre las mujeres que entre los hombres $(29,1$ vs $11,7 \%)$. El $75 \%$ del personal sanitario con COVID-19 son mujeres (MSCBS, 2020).

La distribución de la pandemia en la Comunidad Autónoma de Galicia se muestra en la Tabla 1. En los datos se observa un hecho relevante, la elevada incidencia del síndrome en centros geriátricos donde, de los 1.077 infectados, 762 son usuarios y 315 trabajadores. Así, de los 555 fallecimientos por coronavirus reportados, 249 estaban relacionados con centros gerontológicos, en concreto 128 habrían fallecido en su centro residencial y 121 en un hospital 0 una residencia integrada. Por otra parte, de los 1.049 profesionales sanitarios contagiados, 419 pertenecían a residencias de mayores o centros de personas dependientes (Servicio Galego de Saúde, 2020). 
Tabla 1. Distribución de la pandemia COVID-19 en Galicia a 30 de Abril de 2020.

\begin{tabular}{|c|c|c|}
\hline Total de casos & Infectados activos & $\mathrm{N}^{0}$ fallecidos \\
\hline 9362 & 3486 & 555 \\
\hline \multicolumn{3}{|c|}{ Casos activos por área sanitaria - EOXI } \\
\hline Área Sanitaria - EOXI & Infectados activos & $\mathrm{N}^{0}$ fallecidos \\
\hline A Coruña & 820 & 115 \\
\hline Lugo & 241 & 25 \\
\hline Ourense & 707 & 87 \\
\hline Pontevedra & 214 & 15 \\
\hline Vigo & 848 & 88 \\
\hline Santiago & 498 & 73 \\
\hline Ferrol & 158 & 24 \\
\hline
\end{tabular}

Fuente: Servicio Galego de Saúde. Consellería de Sanidade. Xunta de Galicia.

En Galicia, la coordinación entre los diferentes niveles asistenciales se basa en 2 complementarios, Atención Primaria (AP) y Atención Especializada $(A E)$, dependientes del Servicio Galego de Saúde (SERGAS, Consellería de Sanidade), con asistencia sanitaria presencial, metodología establecida y comunicación bidireccional en la que las tecnologías de la comunicación e información tienen un papel creciente. En cuanto a recursos sociosanitarios para la atención a la dependencia, en concreto personas mayores y personas con necesidades especiales, la Administración, a través de la Consellería de Política Social, diseña y ejecuta un plan estratégico con dotación de recursos y su gestión por medios propios o a través de planes de concertación. Se trata de una estructura asistencial contrastada similar a la de otras áreas geográficas (Arriola et al., 2002).

El envejecimiento de la población gallega y la dispersión poblacional hace que la atención a las personas mayores esté constituida por toda una red de recursos comunitarios e institucionales dependientes directamente de la Administración, de empresas de servicios y del tercer sector. Se trata de modelos altamente heterogéneos, planteamientos dispares y praxis heterodoxas, que defienden una provisión de atención de carácter eminentemente social, pero que precisan del sistema sanitario para aspectos clave como programas de prevención, procedimientos de diagnóstico y terapéutica dado que en ellos viven personas con patologías crónicas severas, necesidad de cuidados de enfermería especializados y gran consumo de fármacos. Este hecho podría cuestionar su modelo, como así parece hacerlo en momentos de emergencia sanitaria aunque también en situaciones de presunta normalidad asistencial como se habría observado previamente (Caamaño, 2008).

Desde el año 2018, la figura del Hospital de Día de Procesos (Servicio de Geriatría, Hospital Universitario Lucus Augusti) constituye una herramienta fundamental para la coordinación entre los sistemas sanitario y de bienestar social en la atención a las personas mayores del área de Lugo. Forma parte de un proyecto de asistencia compartida con cuatro grandes centros residenciales del área, cuyo objetivo principal fue contribuir a la mejora de la calidad de vida de las personas mayores institucionalizadas optimizando los procedimientos diagnósticos y las alternativas terapéuticas limitando hospitalizaciones no necesarias a través de la gestión del caso y la comunicación interprofesional, de modo prioritario en aquellos pacientes frágiles, pluripatológicos, polimedicados, y con perfil multingreso. Esto se consigue a través de interconsulta mensual del equipo geriátrico hospitalario en el centro residencial y contacto permanente a demanda. Para ello existe un protocolo de coordinación entre hospital y centros residenciales que facilita el seguimiento telefónico y derivación para consulta presencial en casos de necesidad. Este proyecto 
incluye facilitar medicación hospitalaria a las residencias para limitar interconsultas presenciales evitables y la estratificación de los pacientes facilitando la toma de decisiones apropiadas a su situación basal.

En la situación actual de pandemia, ha sido precisa una modificación de la sistemática de coordinación en la atención a los pacientes de los centros de personas mayores y se han transformado los procedimientos y las herramientas de comunicación interprofesional. Se redujeron drásticamente las consultas presenciales, las consultas programadas, salvo la incidencia de procesos urgentes, implementando protocolos con el empleo de la tecnología, como consultas y seguimiento de pacientes mediante teleconsulta $u$ otros con los centros en seguimiento, que parecen haber sido adecuados, a juzgar por los resultados provisionales según las estadísticas actualizadas.

Para que este proyecto haya sido efectivo ha requerido una coordinación exahustiva entre los centros sociosanitarios y el Hospital de Día de Geriatría. Se informó inicialmente de las medidas higiénicas y de aislamiento que deberían instaurarse en las residencias de manera precoz, viendo la situación en otras áreas sanitarias. Posteriormente se consultó sobre necesidades materiales (equipos de protección individual, guantes, mascarillas...) con intención de facilitarlos y se revisaron las posibilidades de aislamiento para casos positivos en cada centro residencial. Tras obtener la información sobre los medios disponibles de cada residencia o vivienda comunitaria se estratificó a los pacientes en robustos, prefrágiles y frágiles según dependencia funcional y deterioro cognitivo. Finalmente se programaron llamadas diarias para monitorizar los síntomas de los usuarios y poder llevarse a cabo una intervención precoz con el objetivo de evitar la transmisión. Paralelamente se comenzaron los cribados, tanto de personal como de usuarios, contando con el apoyo de centros de cuidados intermedios para las derivaciones de casos positivos.

En tiempos de crisis sanitaria, la comunicación corporativa adquiere mayor relevancia dado que serán las instituciones públicas de los ámbitos sanitario y social quienes hayan de liderar las estrategias y las acciones. El objetivo ha de ser facilitar la comprensión del problema y sus soluciones (Rincón, 2014) a las que se unirán diferentes organizaciones privadas y del tercer sector afrontando el reto.
En la crisis presente, la comunicación institucional ha sido básica, sin embargo, su ortodoxia (Apolo, Pauker, Pasquel \& Baez, 2017; Riel, 1995) ha tenido que ser modificada por la urgencia del problema. Lo cierto es que experiencias comunicativas previas sobre crisis sanitarias (Fernandez de la Hoz, 2014) desde la administración pública tendrían que hacernos reflexionar en el sentido de la calidad de la información y los grupos a los que va dirigida, en nuestro caso, esencialmente profesionales de la salud, en lo que tiene de comunicación estratégica y sus aspectos reputacionales, aunque esto no haya sido objeto de estudio en nuestro trabajo.

Por otra parte, la comunicación científica, en este caso muy dinámica y productiva, si parece haber influído en la toma de decisiones y se atisba una mayor influencia en el futuro por la demanda profesional y social (Martínez, 2009). Se ha empleado para registrar, verificar y proyectar a través de canales formales e innovadores toda la información relacionada con la epidemiología y las respuestas adaptativas a una situación de pandemia.

El hecho del confinamiento y la limitación de la comunicación presencial explora lo desconocido, modifica la relación directa entre los profesionales de la salud y el paciente, algo básico que ha tenido que adaptarse al momento y a la situación como en ocasiones previas y ha supuesto un uso diferente de los canales de comunicación interprofesional (Cara, Avilés, López, 2018; Fuentes, 2018; Quesada, 2014).

Lacomunicacióntécnicapermanentementeactualizada y emitida desde la Organización Mundial de la Salud ha sido fundamental para la interacción con los pacientes en los distintos niveles asistenciales. La información emitida ha sido recogida por las administraciones públicas nacionales y regionales, adaptada por los diferentes organismos y grupos de interés que interaccionan en la materia lo que ha permitido la optimización continuada de protocolos y medios técnicos a las necesidades de los profesionales para la prevención y asistencia eficiente a los enfermos con patologías agudas y complicaciones de la cronicidad.

\section{Objetivo}

Conocerla influencia que la comunicación técnica producida durante la crisis sanitaria causada por el COVID-19 podrá ejercer sobre la coordinación de la atención geriátrica en la provincia de Lugo y su proyección en Galicia. 


\section{Metodología}

Estudio prospectivo Delphi modificado (Keeney, Hasson \& Mckenna, 2010) a través de una encuesta de doble circulación (Tabla 2), a cumplimentar vía telemática por un grupo de profesionales de la salud expertos en la atención a la población geriátrica gallega constituidos en panel de opinión, $\mathrm{N}=26$, dividido en 2 sub-paneles, el primero constituido por médicos especialistas en Geriatría adscritos al Servicio de Geriatría del Hospital Universitario Lucus Augusti (HULA, Servicio Galego de Saúde - EOXI Lugo), el segundo, formado por profesionales transdisciplinares que trabajan, o lo habían hecho previamente, en alguno de los Centros Gerontológicos participantes en el programa de coordinación con el Hospital de Día de Procesos del Servicio de Geriatría del HULA.

El grupo promotor diseñó y consensuó el cuestionario desglosando temas clave objeto de deliberación y una metodología ad hoc. Además, la selección del panel de expertos (Anexo I) se basó en el nivel de especialización, la experiencia profesional y la participación en actividades científicas relacionadas con la atención al anciano.

El método Delphi, técnica cualitativa diseñada por Olaf Helmer y TJ. Gordon como un instrumento de predicción de una hipotética catástrofe nuclear en el centro de investigación estadounidense RAND Corporation (Kaplan \& Gordon, 1949; Rodriguez, 1999), se definiría como "aquel método que pretende la estructuración de un proceso de comunicación con expertos para la identificación y la convergencia de factores de cambio claves para la construcción cualitativa de escenarios probables, posibles y deseables" (ESUMER, 2013). Ha sido empleado con asiduidad para estudios prospectivos en diferentes áreas del conocimiento como la educación o la salud (Reguant-Álvarez \& Torrado Fonseca, 2016; Yáñez \& Cuadra, 2016). Esta metodología requiere imparcialidad, coherencia y consistencia, además de precisar de la experiencia, el conocimiento, la creatividad y la ética del grupo de expertos en sus apreciaciones colectivas de construcción de futuro. Se trata de un método predictivo subjetivo basado en el juicio intuitivo de los expertos seleccionados que tiene algunas limitaciones como la presentación de cuestiones predeterminadas, el coste en tiempo de ejecución o el equilibrio en el diseño de las preguntas (Varela-Ruiz, Díaz-Bravo \& GarcíaDurán, 2012) pero facilita oportunidades para la reflexión ante problemas concretos.

Para la construcción del cuestionario Delphi se tomaron como base los documentos técnicos relacionados con la crisis del COVID-19 publicados por organismos sanitarios y sociales de la Administración Central y Autonómica, Sociedades Científicas y Colegios Profesionales, Comités de Bioética o la Agencia Española del Medicamento y Productos Sanitarios, entre los meses de marzo y abril de 2020. La intención era incidir en aspectos básicos clínicos, organizativos, de gestión, deontológicos y éticos que podrían condicionar prospectivamente la atención a los ancianos y la comunicación de la misma (Ministerio de Sanidad, Consumo y Bienestar Social, 2020; Centro de Coordinación de Alertas y Emergencias Sanitarias, 2020; Servicio Galego de Saúde, 2020; Dirección Xeral de Saúde Pública, 2020; Sociedad Española de Geriatría y Gerontología. 2020; Consello de Bioética de Galicia, 2020; Asociación Española de Medicamentos y Productos Sanitarios, 2020a; Asociación Española de Medicamentos y Productos Sanitarios, 2020b; Sociedade Galega de Xerontoloxía e Xeriatría, 2020).

La $1^{\text {a }}$ ronda Delphi, incluyó un cuestionario de 20 preguntas relacionadas con aspectos generales de la atención gerontológica y 20 cuestiones específicas basadas en la coordinación geriátrica y la comunicación empleando los documentos técnicos citados. El sistema de puntuación siguió una escala Likert, de 1 a 5 puntos (nivel de acuerdo con la propuesta de muy bajo a muy alto), solicitándose doble respuesta, prioridad de que suceda (deseo) y posibilidad de que lo haga (ocurrencia). Tras 7 días, se lanzó la $2^{a}$ ronda o circulación Delphi empleando las mismas cuestiones adjuntando la media aritmética con una ponderación según fracciones (puntuación inferior a 0,5 puntos supondría el tramo menor, mientras que puntuación superior a 0,5 puntos supondría el tramo mayor) de las respuestas de la $1^{\text {a }}$ ronda al objeto de comprobar si la opinión grupal modificaba las opiniones individuales en la $2^{\mathrm{a}}$ circulación y su rango, por lo tanto, la tendencia global final según procedimiento estadístico descriptivo que será objeto de discusión por las promotoras de la investigación. También se porcentualizó la variación entre niveles de concordancia y discordancia entre grupos e intragrupo. 
Tabla 2. Cuestionario Delphi.

\section{Parte general}

1. Ocurrirá una profunda transformación en la estrategia global de atención a las personas mayores en la Comunidad Autónoma de Galicia.

2. La coordinación entre las Consellerías de Sanidade y Política Social primará la eficiencia y el bien común en la atención al mayor.

3. En las residencias geriátricas, se modificará el modelo asilar dando mayor peso a lo sanitario en la atención a los dependientes dentro de una filosofía de atención individualizada.

4. Serán modificados los criterios técnicos y económicos para la concertación de plazas residenciales públicas con la empresa privada con la exigencia de una gestión profesional.

5. Los procesos de inspección de centros, responsabilidad de la Administración, ganarán en eficiencia modificando el régimen sancionador.

6. Como criterio de transparencia, serán publicadas las condiciones de concertación de plazas, así como las infracciones y las sanciones a empresas de servicios gerontológicos.

7. Serán precisos cambios en el entorno legal y normativo en temas como las incapacitaciones o los documentos de voluntades previas para dar respuesta ágil a situaciones sobrevenidas.

8. Las empresas de servicios gerontológicos responderán efectivamente a las necesidades, las demandas y la problemática que la sociedad les formula actualmente.

9. La presencia de pautas y comportamientos definidos en el Manual de Buenas Prácticas y relacionados con la planificación estratégica y la transparencia de la gestión favorecerá la eficiencia de las empresas de servicios gerontológicos y, en consecuencia, será criterio en el nivel de concertación por parte de la Administración.

10. El hecho de que en centros gerontológicos residan más de un $70 \%$ de pacientes pluripatológicos complejos conllevará un cambio en la estructura de personal médico y de enfermería produciéndose modificaciones de las ratios de personal de atención directa.

11. Las políticas de personal y de carrera profesional atenderán a criterios de igualdad de oportunidades, mérito y capacidad en un proceso transparente y efectivo en las empresas del sector de atención al mayor.

12. Se actualizarán las condiciones laborales y económicas de los distintos niveles profesionales del sector en relación a su necesaria competencia y la relevancia de su ejercicio profesional.

13. En los centros geriátricos, se implantarán Guías de prevención y control frente al COVID-19, del 24 de marzo de 2020, (o similares urgencias sanitarias) que exijan la existencia de "planes de contingencia adaptados a las características de cada centro, dirigidos a la prevención y eventual aparición de casos o brotes de COVID-19".

14. En los centros geriátricos, se implementarán los procedimientos definidos en el "Procedimiento de actuación frente a casos de infección por el nuevo Coronavirus (SARS-CoV-2)".

15. Se potenciarán planes de Responsabilidad Social Empresarial y Humanización de los cuidados en el sector de la Gerontología.

16. Las sociedades científicas en el campo de la Geriatría y la Gerontología y los Colegios Profesionales constituirán un soporte crítico modulador y generador de opinión científica basada en la evidencia en su ámbito de actuación.

17. El Comité de Bioética de Galicia contribuirá como elemento consultivo a la toma de decisiones complejas en la atención a los ancianos dependientes.

18. Organizaciones de consumidores y asociaciones de familiares de residentes constituirán un elemento modelador de la atención en centros residenciales.

19. Será precisa una estrategia de comunicación renovadora de la confianza de la sociedad en las empresas del sector de la Gerontología.

20. La Administración procederá a una política de información transparente en todo lo relacionado con la atención a las personas mayores. 
Tabla 2. Continuación.

\section{Parte específica}

21. Se incentivará la coordinación de proximidad entre Atención Primaria de Salud, equipos de salud de los Centros Gerontológicos y Atención Especializada Geriátrica.

22. La integración de los distintos niveles asistenciales de atención geriátrica constituirá el eje de los cuidados a las personas mayores institucionalizadas.

23. Los servicios de Geriatría se extenderán a todas las EOXI de Galicia como garantía de atención a la población anciana.

24. Se implantará la figura del Geriatra consultor en los Centros de Atención Primaria.

25. Se generalizarán estructuras como el Hospital de Día de Procesos, eje de gestión clínica y soporte de los cuidados clínicos a las personas mayores.

26. La enfermera gestora de casos será el centro de la coordinación entre los diferentes niveles asistenciales geriátricos.

27. Las TICs constituirán un apoyo básico dentro del proceso de coordinación asistencial de la atención geriátrica.

28. Se extenderá la fórmula de teleconsulta geriátrica como instrumento de apoyo a la gestión de casos.

29. La necesaria cancelación de interconsultas presenciales, motivada por la crisis sanitaria, incrementará las tasas de mortalidad por enfermedades crónicas.

30. Una disminución significativa en las derivaciones desde centros gerontológicos a los servicios de urgencias hospitalarios provocará modificaciones en los protocolos al uso.

31. La incidencia del COVID-19 y la intensividad de los cuidados que precisa supondrá un incremento significativo de la prevalencia de grandes síndromes geriátricos.

32. La edad y la expectativa de vida serán criterios de toma de decisión y proporcionalidad en actos, productos, tratamientos y servicios en Geriatría.

33. Se reorientarán los recursos y protocolos de atención paliativa respetando los principios de la bioética con la orientación de los Comités de Ética Asistencial.

34. El modelo de centros residenciales integrados/intermedios (CRI) se implantará como estructura de atención ante situaciones de emergencia sanitaria.

35. En el caso de que los CRI se consideren modelos eficientes, debiera ser exigencia la dirección técnica por un/a médico especialista en Geriatría.

36. Se generalizarán recomendaciones como las realizadas por la Agencia Española de Medicamentos y Productos Sanitarios (AEMPS) del 31 de Marzo de 2020 "para la gestión de medicamentos para el manejo de pacientes con enfermedades en fase terminal o paliativa en la situación sanitaria actual", que facilitan alternativas de optimización terapéutica.

37. En situaciones de emergencia sanitaria, se implementarán protocolos de acompañamiento al paciente con criterios de terminalidad y su comunicación a la familia.

38. Documentos técnicos como la "Guía de actuación frente a COVID-19 en los profesionales sanitarios y sociosanitarios" (versión del 31 de marzo de 2020), contarán con la participación de las Sociedades Científicas y Colegios Profesionales.

39. Se generalizarán documentos como la "Orden SND/322/2020, de 3 de abril, por la que se modifican la Orden SND/275/2020, de 23 de marzo y la Orden SND/295/2020, de 26 de marzo, y se establecen nuevas medidas para atender necesidades urgentes de carácter social o sanitario en el ámbito de la situación de la crisis sanitaria ocasionada por el COVID-19".

40. La Administración implantará una estrategia de comunicación con la ciudadanía que logre transmitir la idea de que una adecuación de la intensidad asistencial, en un escenario de escasez de recursos, no equivale a un abandono del paciente mayor. 


\section{Resultados}

La encuesta fue cumplimentada por profesionales expertos en la atención a las personas mayores desde el ámbito hospitalario y sociosanitario constituídos en panel; $N=26$, edad (rango): $25-63$ años, sexo: 20 mujeres, 6 hombres, divididos en subpanel Geriatras, $n=12(8$ mujeres, 4 hombres) y subpanel Centros Gerontológicos, $\mathrm{n}=14$ (12 mujeres, 2 hombres). La segunda vuelta del estudio fue completada por 7 de los miembros de subpanel de geriatras y por los 14 expertos del subpanel de centros gerontológicos.

La tabla 3 muestra los resultados de media (según ponderación) y rango en los dos paneles de expertos de la encuesta Delphi en las 2 circulaciones. En el subpanel geriatras 14 de las 80 respuestas vieron modificada su puntuación media entre ambas vueltas, sin embargo en sólo 5 de los 80 ítems del subpanel de centros gerontológicos se modificó la puntuación media. Por lo que respecta al rango, en el panel de geriatras, en 44 de las respuestas se estrechó y en 7 se amplió, mientras en el panel centros gerontológicos, en 36 de los 80 ítems se estrechó y en 8 se ensanchó.

$\mathrm{Si}$ a las cuestiones más identificables como documentación técnica, preguntas 13 a 20 y 36 a 40 nos referimos, observamos mínimas diferencias entre paneles de expertos algo previsible y que confirma el hecho de que ese tipo de tansmisión de ideas, métodos y procedimientos, antes perezoso se ha dinamizado adaptándose a las necesidades y a las exigencias de los profesionales.

Al tener en cuenta el nivel de acuerdo intra e intergrupo, la tabla 4 expresa los resultados en número total de respuestas y porcentaje, con una tendencia clara hacia el acuerdo en ambos grupos por incremento de unanimidad, consenso y mayoría, reduciéndose de manera muy notable el porcentaje de discrepancia en las respuestas.

Las figuras 1 y 2 muestran las diferencias entre grupos en las preguntas 10 y 33 en ambas circulaciones siguiendo parámetros descriptivos.

Tabla 3. Resultados cuestionario Delphi.

\begin{tabular}{|c|c|c|c|c|c|c|c|c|c|}
\hline \multirow{3}{*}{\multicolumn{2}{|c|}{ Pregunta }} & \multicolumn{4}{|c|}{ Panel Geriatras } & \multicolumn{4}{|c|}{ Panel Centros Gerontológicos } \\
\hline & & \multicolumn{2}{|c|}{$1^{\text {a } \text { vuelta }}$} & \multicolumn{2}{|c|}{$2^{\mathrm{a}}$ vuelta } & \multicolumn{2}{|c|}{$1^{\mathrm{a}}$ vuelta } & \multicolumn{2}{|c|}{$2^{\mathrm{a}}$ vuelta } \\
\hline & & Media & Rango & Media & Rango & Media & Rango & Media & Rango \\
\hline \multirow[t]{2}{*}{1} & $\mathrm{P}$ & 5 & $4-5$ & 5 & $4-5$ & 5 & $4-5$ & 5 & 5 \\
\hline & 0 & 3 & $2-4$ & 3 & $2-4$ & 3 & $1-4$ & 3 & $2-3$ \\
\hline \multirow[t]{2}{*}{2} & $P$ & 5 & $2-5$ & 5 & 3-5 & 5 & $4-5$ & 5 & 5 \\
\hline & 0 & 3 & $3-4$ & 3 & $2-4$ & 3 & $1-3$ & 2 & $1-3$ \\
\hline \multirow[t]{2}{*}{3} & $\mathrm{P}$ & 4 & $2-5$ & 5 & $4-5$ & 5 & $3-5$ & 5 & $4-5$ \\
\hline & 0 & 3 & $2-4$ & 3 & $3-4$ & 3 & $1-4$ & 3 & $2-3$ \\
\hline \multirow[t]{2}{*}{4} & $P$ & 5 & $3-5$ & 5 & 5 & 5 & $3-5$ & 5 & $4-5$ \\
\hline & 0 & 3 & $1-4$ & 3 & $1-4$ & 2 & $1-4$ & 2 & $1-3$ \\
\hline \multirow[t]{2}{*}{5} & $P$ & 5 & $3-5$ & 5 & $3-5$ & 4 & $3-5$ & 4 & $3-5$ \\
\hline & 0 & 3 & $2-5$ & 2 & $1-3$ & 3 & $2-5$ & 3 & $1-4$ \\
\hline \multirow[t]{2}{*}{6} & $P$ & 4 & 3-5 & 5 & $4-5$ & 5 & $3-5$ & 5 & $4-5$ \\
\hline & 0 & 3 & \begin{tabular}{|l|}
$1-4$ \\
\end{tabular} & 3 & $1-3$ & 3 & $1-4$ & 3 & $1-4$ \\
\hline \multirow[t]{2}{*}{7} & $P$ & 5 & 3-5 & 5 & $2-5$ & 5 & $4-5$ & 5 & $4-5$ \\
\hline & 0 & 3 & $1-4$ & 3 & $2-4$ & 3 & $1-5$ & 3 & $1-3$ \\
\hline \multirow[t]{2}{*}{8} & $P$ & 4 & $2-5$ & 5 & $4-5$ & 5 & $4-5$ & 5 & 5 \\
\hline & 0 & 2 & 1-4 & 2 & 1-4 & 2 & $2-4$ & 2 & $11-3$ \\
\hline \multirow[t]{2}{*}{9} & $P$ & 5 & \begin{tabular}{|l|l}
$4-5$ \\
\end{tabular} & 5 & 4-5 & 4 & $2-5$ & 4 & $4-5$ \\
\hline & 0 & 3 & 1-4 & 3 & 2-3 & 3 & $1-4$ & 3 & $1-3$ \\
\hline \multirow[t]{2}{*}{10} & $P$ & 5 & $4-5$ & 5 & 5 & 5 & $3-5$ & 5 & 5 \\
\hline & 0 & 3 & 1-4 & 3 & 1-4 & 2 & $1-4$ & 1 & 1-2 \\
\hline
\end{tabular}


Tabla 3. Continuación.

\begin{tabular}{|c|c|c|c|c|c|c|c|c|c|}
\hline \multirow{3}{*}{\multicolumn{2}{|c|}{ Pregunta }} & \multicolumn{4}{|c|}{ Panel Geriatras } & \multicolumn{4}{|c|}{ Panel Centros Gerontológicos } \\
\hline & & \multicolumn{2}{|c|}{$1^{\mathrm{a}}$ vuelta } & \multicolumn{2}{|c|}{$2^{\mathrm{a}}$ vuelta } & \multicolumn{2}{|c|}{$1^{\mathrm{a}}$ vuelta } & \multicolumn{2}{|c|}{$2^{a}$ vuelta } \\
\hline & & Media & Rango & Media & Rango & Media & Rango & Media & Rango \\
\hline \multirow[t]{2}{*}{11} & $P$ & 5 & $4-5$ & 5 & 5 & 5 & $4-5$ & 5 & 5 \\
\hline & 0 & 2 & $1-4$ & 2 & $1-4$ & 2 & $1-4$ & 2 & $1-3$ \\
\hline \multirow[t]{2}{*}{12} & $P$ & 5 & $3-5$ & 5 & 5 & 5 & 5 & 5 & $4-5$ \\
\hline & 0 & 2 & $1-3$ & 2 & $1-2$ & 2 & $1-2$ & 2 & $1-3$ \\
\hline \multirow[t]{2}{*}{13} & $P$ & 5 & $4-5$ & 5 & $4-5$ & 5 & $4-5$ & 5 & $4-5$ \\
\hline & 0 & 4 & $2-5$ & 4 & $4-5$ & 3 & $2-4$ & 3 & $2-4$ \\
\hline \multirow[t]{2}{*}{14} & $P$ & 5 & $4-5$ & 5 & 5 & 5 & $3-5$ & 5 & $4-5$ \\
\hline & 0 & 4 & $1-5$ & 4 & $4-5$ & 3 & $1-4$ & 3 & $1-4$ \\
\hline \multirow[t]{2}{*}{15} & $P$ & 5 & $4-5$ & 5 & $4-5$ & 5 & $4-5$ & 5 & $4-5$ \\
\hline & 0 & 3 & $1-4$ & 2 & $1-4$ & 3 & 1-3 & 3 & $1-3$ \\
\hline \multirow[t]{2}{*}{16} & $P$ & 5 & $3-5$ & 5 & $3-5$ & 5 & $4-5$ & 5 & $3-5$ \\
\hline & 0 & 3 & $2-5$ & 3 & $2-4$ & 3 & $1-5$ & 2 & $1-3$ \\
\hline \multirow[t]{2}{*}{17} & $P$ & 5 & $3-5$ & 5 & $3-5$ & 5 & $4-5$ & 5 & $4-5$ \\
\hline & 0 & 3 & $1-4$ & 3 & $1-4$ & 2 & $2-4$ & 2 & $1-2$ \\
\hline \multirow[t]{2}{*}{18} & $P$ & 4 & $3-5$ & 5 & $4-5$ & 4 & $2-5$ & 4 & $3-5$ \\
\hline & 0 & 3 & $2-4$ & 3 & $2-4$ & 3 & $2-4$ & 3 & $2-3$ \\
\hline \multirow[t]{2}{*}{19} & $P$ & 5 & $3-5$ & 5 & $3-5$ & 5 & $3-5$ & 5 & $4-5$ \\
\hline & 0 & 3 & $2-4$ & 3 & $2-3$ & 3 & $2-5$ & 3 & $2-3$ \\
\hline \multirow[t]{2}{*}{20} & $P$ & 4 & $2-5$ & 5 & $4-5$ & 5 & $4-5$ & 5 & $4-5$ \\
\hline & 0 & 2 & $1-4$ & 2 & $1-3$ & 2 & $1-3$ & 2 & $1-3$ \\
\hline \multirow[t]{2}{*}{21} & $P$ & 5 & 5 & 5 & 5 & 5 & 5 & 5 & $4-5$ \\
\hline & 0 & 4 & $2-5$ & 3 & $2-4$ & 3 & $2-4$ & 3 & $2-4$ \\
\hline \multirow[t]{2}{*}{22} & $P$ & 5 & 3-5 & 5 & 5 & 5 & $4-5$ & 5 & $4-5$ \\
\hline & 0 & 3 & $2-5$ & 3 & $2-4$ & 3 & $2-4$ & 3 & $2-4$ \\
\hline \multirow[t]{2}{*}{23} & $P$ & 5 & 5 & 5 & 5 & 5 & $4-5$ & 5 & 5 \\
\hline & 0 & 2 & $1-3$ & 3 & $1-4$ & 3 & $1-4$ & 3 & $1-5$ \\
\hline \multirow[t]{2}{*}{24} & $P$ & 5 & $3-5$ & 5 & 5 & 4 & $3-5$ & 4 & $4-5$ \\
\hline & 0 & 2 & $1-3$ & 2 & $1-3$ & 2 & $1-4$ & 2 & $1-3$ \\
\hline \multirow[t]{2}{*}{25} & $P$ & 5 & $4-5$ & 5 & 5 & 5 & $3-5$ & 5 & $4-5$ \\
\hline & 0 & 3 & $1-4$ & 3 & $2-4$ & 3 & $2-4$ & 3 & $2-4$ \\
\hline
\end{tabular}


68 // Gamonal González et al.

Tabla 3. Continuación.

\begin{tabular}{|c|c|c|c|c|c|c|c|c|c|}
\hline \multirow{3}{*}{\multicolumn{2}{|c|}{ Pregunta }} & \multicolumn{4}{|c|}{ Panel Geriatras } & \multicolumn{4}{|c|}{ Panel Centros Gerontológicos } \\
\hline & & \multicolumn{2}{|c|}{$1^{\text {a }}$ vuelta } & \multicolumn{2}{|c|}{$2^{\mathrm{a}}$ vuelta } & \multicolumn{2}{|c|}{$1^{\text {a }}$ vuelta } & \multicolumn{2}{|c|}{$2^{\mathrm{a}}$ vuelta } \\
\hline & & Media & Rango & Media & Rango & Media & Rango & Media & Rango \\
\hline \multirow[t]{2}{*}{26} & $P$ & 5 & $3-5$ & 5 & $4-5$ & 5 & $3-5$ & 5 & $3-5$ \\
\hline & 0 & 3 & $1-4$ & 3 & $2-4$ & 3 & $2-5$ & 3 & $2-4$ \\
\hline \multirow[t]{2}{*}{27} & $P$ & 5 & $3-5$ & 5 & $4-5$ & 4 & $3-5$ & 4 & $3-5$ \\
\hline & 0 & 4 & $1-5$ & 4 & $2-4$ & 3 & $2-4$ & 3 & $2-4$ \\
\hline \multirow[t]{2}{*}{28} & $\mathrm{P}$ & 5 & $4-5$ & 5 & $4-5$ & 5 & $3-5$ & 5 & $4-5$ \\
\hline & 0 & 4 & $2-5$ & 4 & 3-4 & 3 & $2-4$ & 3 & $2-5$ \\
\hline \multirow[t]{2}{*}{29} & $P$ & 2 & 1-4 & 3 & $1-5$ & 2 & $1-5$ & 2 & $1-3$ \\
\hline & 0 & 4 & $3-5$ & 4 & 3-5 & 4 & $3-5$ & 3 & $2-5$ \\
\hline \multirow[t]{2}{*}{30} & $P$ & 4 & $2-5$ & 5 & $4-5$ & 4 & $3-5$ & 4 & $3-5$ \\
\hline & 0 & 3 & $1-5$ & 3 & $2-5$ & 4 & $3-5$ & 3 & 1-4 \\
\hline \multirow[t]{2}{*}{31} & $P$ & 2 & $1-5$ & 3 & 2-5 & 2 & $1-5$ & 2 & 1-2 \\
\hline & 0 & 4 & $1-5$ & 4 & 4-5 & 4 & $3-5$ & 4 & $3-5$ \\
\hline \multirow[t]{2}{*}{32} & $P$ & 4 & $1-5$ & 4 & 4-5 & 3 & $1-5$ & 3 & $1-5$ \\
\hline & 0 & 4 & $2-5$ & 4 & $1-5$ & 4 & $3-5$ & 4 & $4-5$ \\
\hline \multirow[t]{2}{*}{33} & $P$ & 5 & $4-5$ & 5 & $4-5$ & 5 & $4-5$ & 5 & $4-5$ \\
\hline & 0 & 3 & $2-5$ & 3 & 2-4 & 3 & $2-5$ & 3 & $2-5$ \\
\hline \multirow[t]{2}{*}{34} & $P$ & 5 & $3-5$ & 5 & 3-5 & 4 & $2-4$ & 4 & $2-5$ \\
\hline & 0 & 4 & $2-5$ & 4 & 3-4 & 3 & 2-4 & 3 & $1-5$ \\
\hline \multirow[t]{2}{*}{35} & $P$ & 5 & $4-5$ & 5 & 4-5 & 4 & 3-5 & 4 & 3-5 \\
\hline & 0 & 3 & 1-4 & 3 & $1-4$ & 3 & 1-3 & 3 & 2-4 \\
\hline \multirow[t]{2}{*}{36} & $P$ & 5 & $4-5$ & 5 & $4-5$ & 5 & $3-5$ & 5 & $4-5$ \\
\hline & 0 & 4 & $1-5$ & 3 & $1-4$ & 3 & $2-4$ & 3 & $2-4$ \\
\hline \multirow[t]{2}{*}{37} & $P$ & 5 & $4-5$ & 5 & $4-5$ & 5 & $4-5$ & 5 & 5 \\
\hline & 0 & 3 & $2-4$ & 3 & 1-4 & 3 & 3-4 & 3 & 2-4 \\
\hline \multirow[t]{2}{*}{38} & $P$ & 5 & $4-5$ & 5 & 5 & 5 & $3-5$ & 5 & 5 \\
\hline & 0 & 4 & $2-5$ & 4 & $1-5$ & 3 & $2-4$ & 3 & $2-5$ \\
\hline \multirow[t]{2}{*}{39} & $P$ & 5 & $3-5$ & 5 & 4-5 & 4 & $3-5$ & 4 & $4-5$ \\
\hline & 0 & 4 & 3-5 & 4 & 4 & 3 & $2-3$ & 3 & 3 \\
\hline \multirow[t]{2}{*}{40} & $P$ & 5 & $1-5$ & 5 & 5 & 4 & $2-5$ & 4 & 3-5 \\
\hline & 0 & 4 & $2-5$ & 4 & 2-4 & 3 & 1-4 & 3 & 2-4 \\
\hline
\end{tabular}


Tabla 4. Grado de acuerdo en las 80 respuestas de los 2 subpaneles en la doble circulación Delphi (total y \%).

\begin{tabular}{|c|c|c|c|c|c|c|c|c|}
\hline & \multicolumn{4}{|c|}{ Panel Geriatras } & \multicolumn{4}{|c|}{ Panel Centros Gerontológicos } \\
\hline & \multicolumn{2}{|c|}{$1^{\mathrm{a}}$ vuelta } & \multicolumn{2}{|c|}{$2^{a}$ vuelta } & \multicolumn{2}{|c|}{$1^{a}$ vuelta } & \multicolumn{2}{|c|}{$2^{\mathrm{a}}$ vuelta } \\
\hline & Total & $\%$ & Total & $\%$ & Total & $\%$ & Total & $\%$ \\
\hline Unanimidad & 2 & 2.5 & 13 & 16.25 & 2 & 2.5 & 9 & 11.25 \\
\hline Consenso & 15 & 18.75 & 26 & 32.5 & 16 & 20.0 & 26 & 32.5 \\
\hline Mayoría & 25 & 31.25 & 23 & 28.75 & 37 & 46.25 & 31 & 38.75 \\
\hline Discrepancia & 38 & 47.5 & 18 & 22.5 & 25 & 31.25 & 14 & 17.5 \\
\hline & 80 & $100 \%$ & 80 & $100 \%$ & 80 & $100 \%$ & 80 & $100 \%$ \\
\hline
\end{tabular}

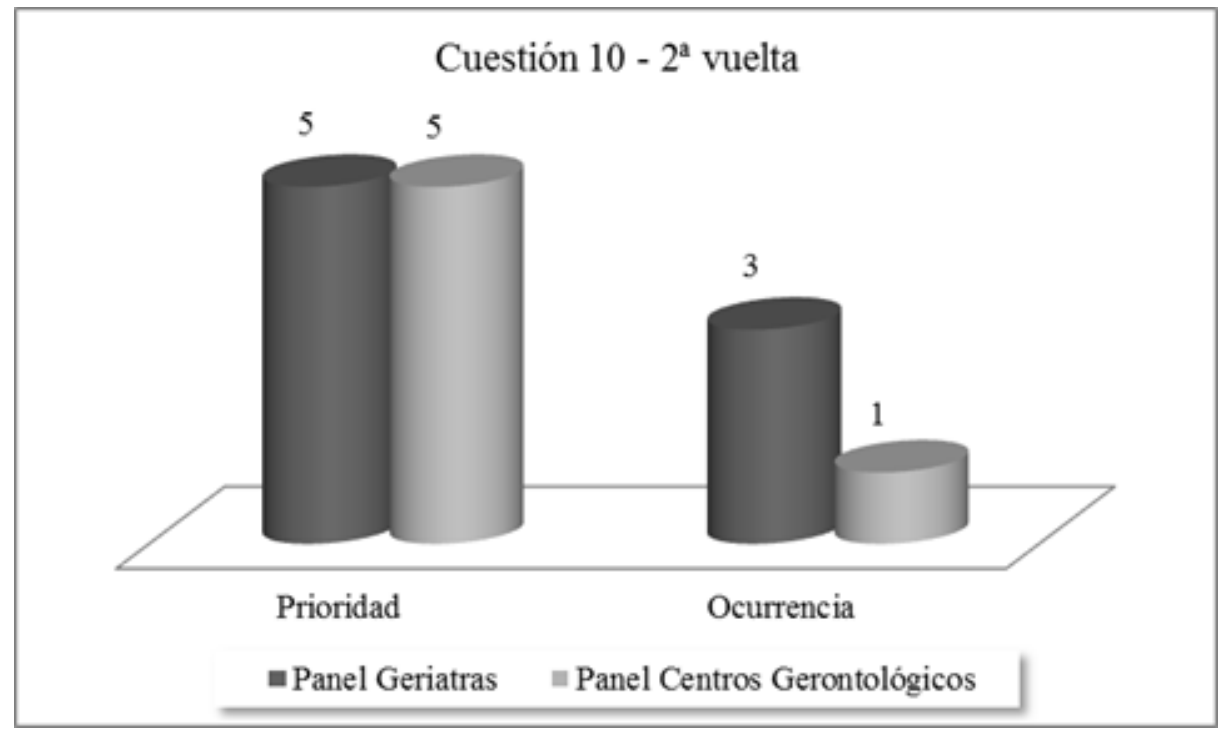

Figura 1. Cuestión 10 "El hecho de que en los centros gerontológicos residan más de un $70 \%$ de pacientes pluripatológicos complejos conllevará un cambio en la estructura de personal médico y de enfermería produciéndose modificaciones de las ratios de personal de atención directa". Rango: Prioridad 5 (Panel Geriatras) vs 5 (Panel Centros Gerontológicos). Ocurrencia 1-4 (Panel Geriatras) vs 1-2 (Panel Centros Gerontológicos).

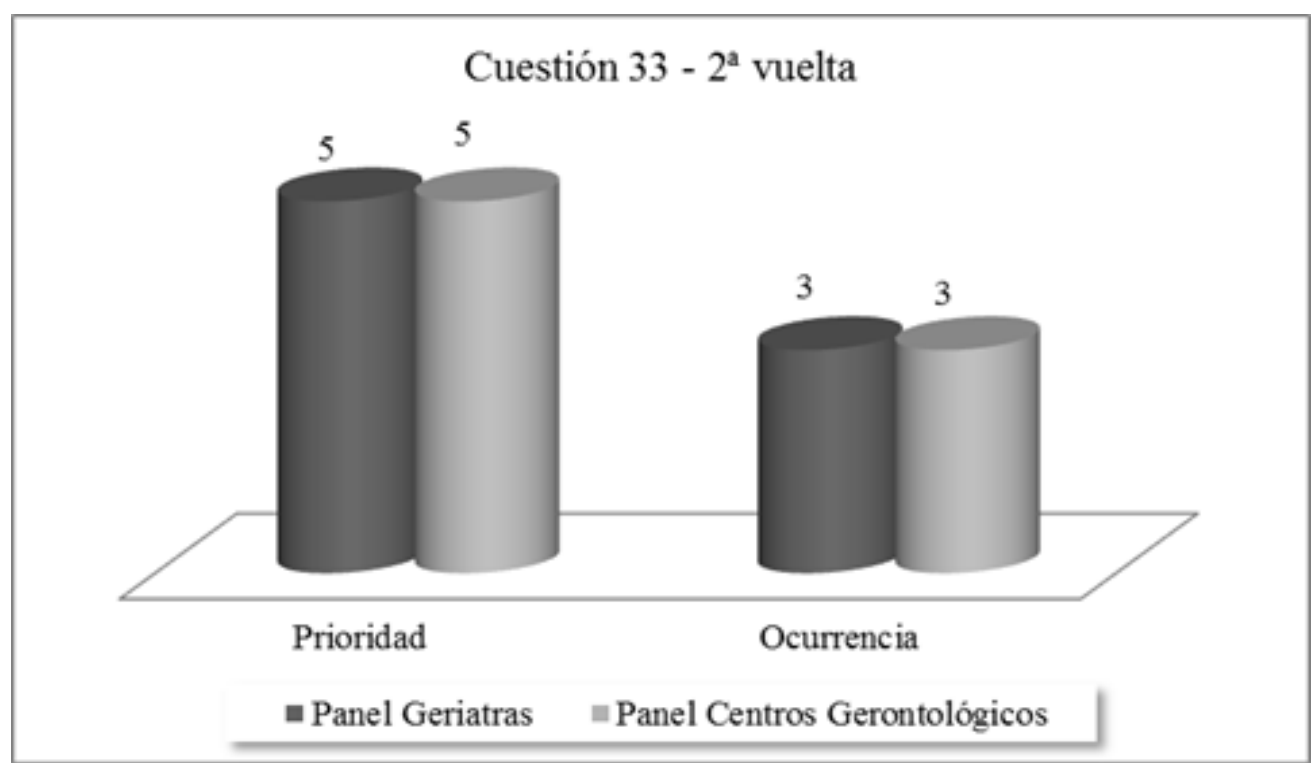

Figura 2. Cuestión 33 "Se reorientarán los recursos y protocolos de atención paliativa respetando los principios de la bioética con la orientación de los Comités de Ética Asistencial". Rango: Prioridad 4-5 (Panel Geriatras) vs 4-5 (Panel Centros Gerontológicos). Ocurrencia 2-5 (Panel Geriatras) vs 2-5 (Panel Centros Gerontológicos). 


\section{Discusión}

Presuponiendo que el hecho de que el medio de atención a las personas mayores, Hospital versus Centro Gerontológico, podría aportar matices cualitativos a la opinión de los profesionales, decidimos plantear el estudio dividiendo a los expertos en 2 subpaneles en contra de lo habitual, un solo grupo evolutivo según circulaciones de la encuesta. Es importante destacar que el doble planteamiento de las cuestiones, prioridad y posibilidad de que ocurra, enriquece las propuestas introduciendo los aspectos fundamentales además del vaticinio prospectivo del grupo experto sobre una necesidad percibida.

Aunque la metodología elegida sea cualitativa, los resultados de la investigación aportan matices cuantitativos en lo que respecta a medias poderadas, rangos y nivel de acuerdo. Si bien algunos autores sugieren que la moda es el parámetro estadístico más adecuado para la evaluación de las respuestas (Godet, 1996). Nuestro trabajo parametriza en base a la media como medida de tendencia central y los rangos que permiten observar el grado de dispersión de las respuestas replicando investigaciones previas (Caamaño, Donis, Fernández, Seoane, Del Monte \& Vilas, 2005). Puede observarse que la media de las respuestas apenas muestra diferencias, no sólo entre ambos grupos de expertos, sino entre las dos rondas de la encuesta en cada uno de los subpaneles, hallazgo relacionado con el nivel de acuerdo real entre los expertos, sin descartar que la presentación de cuestiones cerradas limite la discrepancia, característica metodológica de este tipo de estudios (Varela-Ruiz et al., 2012; López Gómez, 2018).

Por lo que al rango respecta, la aproximación de ambos subpaneles apunta a un proceso de cuantificación reflexiva condicionada por la opinión del grupo. Este resultado reforzaría análisis previos en los que se observa que el método Delphi favorece que en la segunda circulación, el conocimiento de las puntuaciones medias del grupo tras la primera ronda, tienda a modificar la puntuación individual de modo que se acorten las diferencias entre rondas, por lo que el rango de las respuestas suele estrecharse al final lo que acerca al consenso (Caamaño, Gandoy \& Del Monte, 2015).

Creemos que resulta muy significativo el hecho de que a medida que circula la encuesta, las respuestas a las cuestiones tiendan al acuerdo como se puede observar en la tabla 4, pues en ambos grupos no sólo se incrementa el porcentaje de unanimidad, sino que también se minimizan las discrepancias en favor del consenso o la mayoría, algo previamente observado en estudios metodológicamente similares (Fernández Ávila, Rojas Roselli, 2019) y que resulta de especial relevancia prospectiva.

La situación de pandemia y la naturaleza del estudio, lo inédito del momento, limitan la comparación dado que no hemos encontrado publicaciones con temática y metodología similares, hecho que creemos confiere valor a nuestro trabajo. Ésta es la razón por la que comentaremos las respuestas de forma agrupada teniendo en cuenta investigaciones previas relacionadas con diversas disciplinas y temas dispares (Alshehri, Rezgui \& Li, 2015; Farrel, Tsang, Raman-Wilms, Irving, Conklin \& Pottie, 2015; López Vidal \& Calvo Lluch, 2019).

Para encontrar situaciones referenciales, en cuanto a crisis sanitarias y comunicación, tendríamos que hacer alusión a lo vivido en el caso de la Gripe A o la crisis del virus Ébola, aunque los estudios localizados tengan objetivos y metodología muy diferentes al de nuestro trabajo (Coronado, Catalán, Martínez, 2011; Micaletto \& Gallardo, 2015; Guzmán, 2018). Entendemos que es lógico por la presentación de la pandemia, y abren un camino que, sin duda, seguirán otros autores analizando la información científica, la ofrecida por la prensa escrita o la presente en las redes sociales, de enorme interés como en otras patologías (Caamaño, Arnejo, Carrera, Pérez \& Vilas, 2003).

Contextualizando, podríamos construir un primer bloque formado por aquellas preguntas que hacen referencia a las estrategias de atención a personas mayores, la coordinación interinstitucional y su gobernanza o los criterios técnicos de concertación e inspección. Ambos paneles consideran prioritaria la transformación de las estrategias relacionadas con la atención a las personas mayores y dependientes, con un nivel medio de convencimiento. Creemos que la publicación del informe anual del Defensor del Pueblo correspondiente al año 2019, en concreto la separata "Atención a personas mayores. Centros residenciales", entregado al Parlamento el miércoles, día 13 de mayo de 2020, refuerza notablemente la opinión de los expertos de nuestro estudio pues incide en la necesidad de cambios profundos en el sistema, denunciando el déficit de plazas residenciales, la heterogeneidad normativa, la necesaria actualización legislativa para situaciones de emergencia, la deficiente atención sanitaria proporcionada por los centros, la imprescindible revisión al alza de los ratios de personal, además de la transparencia en los concursos y las sanciones por incumplimiento (Defensor del Pueblo, 2019). En este sentido, Caamaño \& Vilas (2012) habían planteado algunas propuestas que podrían facilitar una gestión estratégica de los servicios sociales y la atención 
a la dependencia teniendo como centro del sistema a la persona mayor y la cobertura de sus necesidades expresadas, antes que las necesidades del sector, lo cual bien se podría extrapolar a la situación objeto del presente estudio.

El modelo de atención, la coordinación entre niveles asistenciales y los procedimientos han tenido que ser necesariamente modificados en la medida en que la prioridad era la atención a un proceso agudo que de forma potencial descompensaría la pluripatología de los ancianos y acentuaría debilidades sistémicas. Se ha tenido que pasar de una asistencia presencial a otra facilitadora de recursos, telemática y de contacto permanente entre técnicos para proporcionar una atención adecuada sin sobrecargar el sistema sanitario por procesos no urgentes pero sin minimizar la relevancia de lo necesario.

Sin duda el nivel de especialización de los servicios y el nivel de superespecialización sobrevenida de los profesionales ha sido clave, creemos que de éxito, como lo demuestran los datos desagregados por áreas sanitarias (Tabla 1) y que debería ser estudiado con detalle para prever futuros escenarios. Aquí se observan algunas discrepancias entre paneles sobre la conveniencia de instaurar la figura del geriatra como clave del sistema, la protocolización de consultas telemáticas, el impacto de la TICs en la actividad clínica o la potencial discriminación por edad en la toma de decisiones, sin duda por el entorno de trabajo. Sin embargo, si parece existir consenso en la repercusión que la demora de interconsultas o la centralización de los recursos en procesos agudos podría suponer para los cuidados de continuidad y crónicos a los residentes. Se han tenido que adaptar los procesos de comunicación habitual para el control de enfermedades (Catalán, Muñoz-Cruzado \& Barba, 2010) en la relación interinstitucional, interprofesional, y con los pacientes, dando paso a la facilitación empleando las tecnologías de la información y la comunicación.

Aspectos clave para la atención al adulto mayor como los relacionados con políticas de personal, especialmente afectado durante la pandemia como responsable de la salud de los pacientes y segunda víctima grupal del COVID-19 (con polémica documental y legal asociada), mostraron la necesidad de equilibrar ratios de atención directa y dignificar el trabajo y la carrera profesional, propuesta ante la cual manifiesta un evidente pesimismo el subpanel de expertos de centros gerontológicos (Figura 1). En ello insiste también el documento referido del Defensor del Pueblo que remarca la necesidad de un plan de formación específico para el personal de atención directa además de la imprescindible dignificación de su labor y la ampliación de un modelo sociosanitario en el que el personal médico y de enfermería adscrito a los centros sea clave en los procesos de atención.

La producción científico-técnica sobre el abordaje de la situación sanitaria generada por el COVID-19 ha sido incesante con actualizaciones diarias por parte de administraciones, empresas y editoriales científicas, también en la atención a las personas mayores durante la pandemia. Se han generado todo tipo de decretos, órdenes, recomendaciones y estrategias de atención y tratamiento que creemos marcarán el futuro de la sanidad en España. Se aprecia un mayor convencimiento sobre lo prioritario que resultará esta operativa en situaciones venideras, fundamentalmente por parte del subpanel geriatras, que consideramos razonable en la medida en la cual la innovación en procedimientos diagnósticos y alternativas terapéuticas son propias del medio hospitalario por su orientación a la tipificación, el diagnóstico diferencial y la provisión de cuidados en cuadros agudos o de media estancia como los requeridos por el síndrome COVID-19 o similares epidemias (Folayan, Haire, Allman, Yakubu, \& Muhammed, 2018).

Consideramos decisivo el factor innovación en la producción científico-técnica para la modificación de los criterios en ambos paneles asociado a la experiencia diaria en una situación como ésta lo que favorece el análisis crítico y su aplicación inmediata con transferencia inmediata a los profesionales. Desde la prospectiva éste es el factor determinante del futuro del sector en la medida en la que ha modificado las relaciones interprofesionales e interinstitucionales.

Sobre la influencia que organizaciones externas como colegios profesionales, asociaciones de usuarios o comités consultivos tendrán en el sector, los expertos consideran necesario poner en valor su potencial, sin embargo, específicamente el subpanel de centros gerontológicos, manifiesta sus reservas ante tal posibilidad seguramente influidos por la escasa comunicación de las acciones de estas entidades en el nivel asistencial de los centros geriátricos.

Si la comunicación interna, profesional, entre las diferentesestructurasdelsectordeatenciónalaspersonas mayores parece esencial, no menos lo es la información que desde la Administración y el sector empresarial se transmite a la opinión pública y, específicamente, a las familias de las personas institucionalizadas que han visto modificada la sistemática de interacción y que han podido tener la sensación de que las limitaciones de los recursos discriminaban a las personas mayores. Los 
datos hablan por sí sólos, aproximadamente un $45 \%$ de las personas fallecidas en Galicia vivían en centros geriátricos, circunstancia ésta que exige reflexión y acción. Aquí, el comportamiento de los paneles no es simétrico por la relevancia o no del hecho de que el sector modifique su estrategia de comunicación o que la Administración sea transparente en la información sobre el sector residencial, en este caso el subpanel de centros manifiesta un cierto escepticismo.

Quizás la principal limitación de la investigación que presentamos estaría relacionada con la configuración de un panel de expertos muy delimitado geográficamente, con un servicio de Geriatría bien estructurado y de gran experiencia, desafortunadamente inexistente en otras áreas sanitarias de Galicia, hecho que podría influir en la capacidad prospectiva del consenso y en su extrapolación a realidades asistenciales diferentes en situaciones concretas, como ésta, de urgencia sanitaria y heterodoxia organizativa. Pese a todo, creemos que nuestro estudio permite afirmar que la crisis del COVID-19 ha hecho evidente que la atención sanitaria de las personas institucionalizadas dependerá de los equipos de Atención Primaria y Atención Especializada del sistema público de salud, muy especialmente de los servicios de Geriatría, sin olvidar al personal médico y de enfermería de los propios centros gerontológicos que hacen un trabajo de prevención, soporte clínico y coordinación interinstitucional de valor inestimable mas nunca suficientemente valorado y con escasos recursos. Otra cosa es la comunicación de las empresas del sector y sus directivos quienes aún en situaciones límite como la actual insisten en el perfil social de los centros obviando la ingente problemática sanitaria de los clientes a quienes ofrecen sus servicios, algo que sin duda conocen bien pues el perfil está marcado por el sobreenvejecimiento, la dependencia funcional, la pluripatología y la polimedicación (Imaginario, Machado, Antunes \& Martins, 2018) además de lo explicitado en el informe anual del Defensor del Pueblo del año 2019.

El debate sobre el futuro de la atención a las personas mayores dependientes continuará abierto durante tiempo, habrá que resolver cuestiones relacionadas con la modificación del sistema de gestión y del modelo de atención, la necesaria planificación estratégica del sector, la reducción de prácticas heterodoxas y sus consecuencias legales, la coordinación entre lo sanitario y lo social, la incentivación de estructuras como los hospitales de día de procesos geriátricos o la presencia de equipos de Geriatría de proximidad en los centros de atención primaria y su relación con los exigibles equipos clínicos (enfermería y medicina) de los propios centros que contribuirán al necesario giro del sector a la resolución de la problemática de los clientes para lograr una atención de calidad a las personas mayores institucionalizadas.

\section{Conclusiones}

Esperando que la investigación planteada ayude a la deliberación sobre el futuro de la atención en Geriatría y Gerontología en Galicia desde la pausa y la crítica constructiva, podríamos establecer tres conclusiones esenciales. La primera implicaría que la documentación técnica generada por instituciones internacionales, nacionales y autonómicas podría haber sido esencial para las estrategias de resolución de la pandemia en el área de estudio desde los servicios de Geriatría y los centros geriátricos. En segundo lugar la estrategia de comunicación bidireccional, promovida por las instituciones y secundada por los profesionales, parece haber favorecido la coordinación entre niveles asistenciales en el área sanitaria de Lugo, optimizando los procesos haciéndolos sostenibles y promoviendo el empleo de canales tecnológicos que han mostrado eficacia. Finalmente creemos que en el caso de una réplica de situaciones sanitarias críticas como la actual, la experiencia adquirida en la coordinación y la metodología, apoyada en una comunicación técnica proactiva e innovadora, contribuirá a la mejora de las expectativas de salud de las personas mayores.

Agradecimientos

A las y los profesionales que han constituido el panel de expertos.

\section{Referencias bibliográficas}

Agencia Española de Medicamentos y Productos Sanitarios. (2020a). Recomendaciones de la AEMPS para la gestión de medicamentos para el manejo de pacientes con enfermedades en fase terminal o paliativa en la situación sanitaria actual. https://www.aemps.gob.es/informa/ notasinformativas/medicamentosusohumano-3/2020medicamentosusohumano-3/recomendaciones-dela-aemps-para-la-gestion-de-medicamentos-parael-manejo-de-pacientes-con-enfermedades-en-faseterminal-o-paliativa-en-la-situacion-sanitaria-actual/.

Agencia Española de Medicamentos y Productos Sanitarios. (2020b). Tratamientos disponibles para el manejo de la infección respiratoria por SARSCoV-2. https://www.aemps.gob.es/laAEMPS/docs/ 
medicamentos-disponibles-SARS-CoV-2-27-3-2020. pdf?x47154.

Alshehri, S.A., Rezgui, Y., \& Li, H. (2015). Delphi-based consensus study into a framework of community resilience to disaster. Nat Hazards, 75, 2221-2245. Doi.org/10.1007/s11069-014-1423-x.

Apolo, D., Pauker, L., Pasquel, G., \& Baez, V. (2017). Gestión de Comunicación Corporativa: consideraciones para el abordaje de su estudio y práctica Corporate Communication Management: Considerations for the approach to its study and practice. Revista Latina de Comunicacion Social, 521-539. 10.4185/RLCS-72-2017-1177.

Arriola, E., García Navarro, J.A., Fernández Viadero, C., Alaba Trueba, J., Varona Alonso, M.A., Maturana Navarrete, N., ... Reuss Fernández, J. (2002). Papel de los distintos niveles asistenciales geriátricos en la atención al paciente con demencia. Revista Española de Geriatría y Gerontología, 37(s4), 26-34.

Bonanad, C., García-Blas, S., Tarazona-Santabalbina, F.J., Díez-Villanueva, P., Ayesta, A., Fores, J.S., ... Martiınez-Selles, M. (2020). Coronavirus: la emergencia geriátrica de 2020. Documento conjunto de la Seccion de Cardiología Geriatrica de la Sociedad Española de Cardiología y la Sociedad Espanola de Geriatría y Gerontoloíla. Revista Española de Cardiología, in press, 1-21. Doi: 10.1016/j. recesp.2020.03.027.

Caamaño Ponte, J. L., Arnejo García, N., Carrera Iglesias, B., Pérez Suárez, D., \& Vilas Martínez, M.A. (2003). Presencia de la enfermedad de Alzheimer en la prensa escrita de Galicia. Estudio comparativo entre medios. Agathos. Atención Sociosanitaria y Bienestar, 3(2), 38-43.

Caamaño, J., Donis, L., Fernández, P., Seoane, F., Del Monte, A., \& Vilas, M. (2005). Servicios sociales especializados para personas mayores dependientes en Galicia. Resultados de un estudio prospectivo Delphi. Agathos. Atención Sociosanitaria y Bienestar, 5(4), 26-34.

Caamaño Ponte, J. L. (2008). Servicios Sociales: una visión desde la empresa. Edita ISISS.

Caamaño Ponte, J.L. \& Vilas Martínez, M. (2012). DAFO del sistema de atención al mayor dependiente en Galicia "Revisitado". Agathos. Atención Sociosanitaria y Bienestar, 12(2).
Caamaño Ponte, J., Gandoy Crego, M., \& Del Monte Pérez, A. (2015). Asociaciones de Familiares de Enfermos de Alzheimer de Galicia y Responsabilidad Social Corporativa. Neurama. Revista Electrónica de Psicogerontología, 2(1).

Cara Rodríguez, R., Avilés Sáez, Z., López Trinidad, L.M. (2018). Comunicación y escucha activa por parte del profesional de enfermería a pacientes con cáncer ginecológico: una revisión bibliográfica. Revista Española de Comunicación en Salud, 9(2), 221229. https://doi.org/10.20318/recs.2018.4500.

Catalán-Matamoros, D., Muñoz-Cruzado y Barba, M., \& Fuentes Hervías, M.T. (2010). Técnicas de comunicación para la prevención y el control de enfermedades. Revista Española de Comunicación en Salud, 1(1), 50-65.

Centro de Coordinación de Alertas y Emergencias Sanitarias. (2020). Actualización n 91: enfermedad por SARS-CoV-2 (COVID-19) 30.04.2020. https:// www.mscbs.gob.es/profesionales/saludPublica/ ccayes/alertasActual/nCov-China/documentos/ Actualizacion_91_COVID-19.pdf

Consello de Bioética de Galicia. Crise sanitaria causada polo Covid-19. Algunhas consideracións éticas. https://www.sergas.es/Bioetica/Documents/151/2020Crisis-sanitaria-causasda-por-el-COVID-19-Algunasconsideraciones-eticas.pdf.

Coronado Robles, R., Catalán-Matamoros, D., \& Martínez González, E. (2011). La gripe A (H1N1) en prensa. Revista Española Comunicación en Salud, 2(1), 32-45.

Defensor del Pueblo. (2019). Informe anual del Defensor del Pueblo. Atención a personas mayores. Centros residenciales. Recupeardo de www. defensordelpueblo.es.

Dirección Xeral de Saúde Pública da Consellería de Sanidade. (2020). https://saladecomunicacion. sergas.gal/Paginas/DetalleNova.aspx?idioma=ga\&id Nova $=10399 \&$ vista=clasica. $h t$ ttps://www.sergas.es/.

ESUMER. (2013). Documento metodológico para el diseño y aplicación del método Delphi en la Prospectiva Laboral Cualitativa. Medellín, Colombia: Fundación Institución Universitaria ESUMER.

Farrel, B., Tsang, C., Raman-Wilms, L., Irving, H., 
Conklin, J., \& Pottie, K. (2015). What are priorities for deprescribing for elderly patiens? Capturing te voice of practicioners: a modified Delphi process. PLOS ONE, 10(4), e0122246. Doi: 10.1371/journal. pome. 0122246 .

Fernández-Ávila, D.G., Rojas, M.X., Roselli, D. (2019). El método Delphi en la investigación en reumatología: ¿lo estamos haciendo bien? Revista Colombiana de Reumatología, in press. https://www.elsevier. es/es-revista-revista-colombiana-reumatologia374-pdf-S0121812319300374. DOI: 10.1016/j. rcreu.2019.04.001.

Fernández de la Hoz, K. (2014). La comunicación en crisis sanitarias: perspectiva de las administraciones públicas. Revista Española de Comunicación en Salud, 5(1), 14-19

Folayan, M.O., Haire, B., Allman, D. Yakubu, A., \& Muhammed. O. (2018). Research priorities during infectious disease emergencies in West Africa. Research priorities during infectious disease emergencies in West Africa. BMC Res Notes, 11, 159. Doi.org/101186/s13104-018-3263-3.

Fuentes-Colmenero, A.L. (2019). Características de la comunicación entre profesionales de enfermería y medicina para la seguridad del paciente. Revista Española de Comunicación en Salud, 10(2), 160170. https://doi.org/10.20318/recs.2019.4326.

Godet, M. (1996). Manual de Prospective Strategique. Paris: Dunod.

Guía de actuación frente a COVID-19 en los profesionales sanitarios y socio-sanitarios. Recuperado de https://www.mscbs.gob.es/ profesionales/saludPublica/ccayes/alertasActual/ nCov-China/documentos/Protocolo_Personal_ sanitario_COVID-19.pdf.

Guzmán do Nascimento, B. (2018). Comunicación y salud: La gestión de la crisis del Ébola a través de las redes sociales. Revista Española de Comunicación en Salud, 9(2), 196-202.

Imaginario,C.,Machado,P.,Antunes,C.,\&Martins, T.(2018). Perfil funcional de los ancianos institucionalizados en residencias: estudio piloto. Gerokomos, 29(2), 59-64. Recuperado de http://scielo.iscii.es/scielo. php?script=sci_arttext\&pid=S1134-928X2018000200 059\&lng=es\&tlng=es.
Kaplan, A., Skogstad, A.L., \& Girshick, M.A. (1950). The Prediction of Social and Technological Events. The Prediction of Social and Technological Events. Public Opinion Quarterly, 14(1), 93-110. Doi. org/10.1086/266153.

Keeney, S., Hasson, F., \& Mckenna, H. (2010). The Delphi Technique in Nursing and Health Research. West Sussex: John Wiley \& Sons Ltd.

López Gómez, E. (2018). El método Delphi en la investigación actual en educación: una revisión teórica y metodológica. Educación XX1, 21(1), 17-40.

López Vidal, FJ. \& Calvo Lluch, A. (2019). Diseño y evaluación mediante Método Delphi de un cuestionario para conocer las características de la actividad física en personas mayores que viven en residencias. Retos, 36, 515-520.

Martínez Rodríguez, A. (2009). Comunicación científica: de su necesidad a las redes y comunidades. Reseñas $y$ reflexiones, 5(5), 63-67.

Micaletto Belda, J.P., \& Gallardo Vera, L. (2015). La comunicación interinstitucional en la crisis del ébola en Europa: el caso de la crisis española en sus inicios. Revista Internacional de Relaciones Públicas, 5(9),89-110.

Ministerio de Sanidad, Consumo y Bienestar Social. (2020). Informe sobre la situación de COVID-19 en España. Informe COVID-19 n²7. 30 de abril de 2020. Gobierno de España.

Quesada Varela, V.J. (2014). Ébola y Nuevas Tecnologías. Cadernos de Atención Primaria, 20, 210-211.

Reguant-Álvarez, M., \& Torrado Fonseca, M. (2016). El método Delphi. Revista d'innovació i recerca en Educació, 9(1), 87-102.

Riel, C. B. M. van. 1995. Principles of corporate communication. New York, EUA: Prentice Hall, 1995.

Rincón Quintero, Y. (2014). Vinculación de relaciones públicas, comunicación corporativa, y logística en la organización. Revista Encuentros, 12(1), 47-59.

Rodriguez, J.L. (1999). El método Delphi. Una técnica de previsión para la incertidumbre. Barcelona, España: Ariel.

Servicio Galego de Saúde. (2020). Consellería de Sanidade. Xunta de Galicia. 
Sociedad Española de Geriatría y Gerontología. (2020). Recomendaciones éticas y clínicas para la toma de decisiones en el entorno residencial en contexto de la crisis de COVID-19. Sociedad Española de Geriatría y Gerontología. Recuperado de https://www.segg.es/actualidad-segg/2020/04/07/ recomendaciones-residencias-covid-19.

Sociedade Galega de Xerontoloxía e Xeriatría (2020). Posicionameto da Sociedade Galega de Xerontoloxía e Xeriatría ante a situación actual nas residencias de persoas maiores. Recuperado de https://sgxx.org/posicionamento-da-sociedadegalega-de-xerontoloxia-e-xeriatria-ante-a-situacionactual-nas-residencias-de-persoas-maiores.

Varela-Ruiz, M., Díaz-Bravo L., \& García-Durán, R. (2012). Descripción y usos del método Delphi en investigaciones del área de la salud. Investigación en Educación Médica, 1(2), 90-95.

Wang, C., Horby, P.W., Hayden, F.G., \& Gao, G.F. (2020). A novel coronavirus Outbreak of global health concern. The Lancet, 395, 470-473. Doi: 10.1016/ S0140-6736(20)30185-9.

Yáñez Gallardo, R., \& Cuadra Olmos, R. (2018). La técnica Delphi y la investigación en los servicios de salud. Ciencia y Enfermería, 14(1), 9-15, 2008. 
Anexo I. Panel de expertos.

\begin{tabular}{|c|}
\hline $\begin{array}{c}\text { Subpanel Geriatras } \\
\text { Médicos especialistas en Geriatría. Servicio de Geriatría Hospital Universitario Lucus } \\
\text { Augusti. SERGAS }\end{array}$ \\
\hline $\begin{array}{l}1{ }^{*} \text { José Ramón Martínez Calvo, }{ }^{1 *} \text { Casiano López Piñeiro, }{ }^{1 *} \text { Sonia Barros Cerviño, }{ }^{1 *} \text { Javier } \\
\text { Vidal López, }{ }^{*} \mathrm{M}{ }^{a} \text { Mar Magariños Losada, }{ }^{1 *} \text { Ana Martín Graczyk, }{ }^{1 *} \mathrm{M} \text { Del Rocío Malfeito } \\
\text { Jiménez, }{ }^{* *} \text { Laura Gamonal González, }{ }^{1 *} \text { Manuel Melero Brezo, }{ }^{2 *} \text { Sandra Nieto Cano, } \\
\text { 2*} \text { Laila Dib Paz, }{ }^{2 *} \text { Vanessa Álvarez Vidal }\end{array}$ \\
\hline $\begin{array}{l}\text { Subpanel Centros Gerontológicos } \\
\text { Expertos Transdisciplinares }\end{array}$ \\
\hline 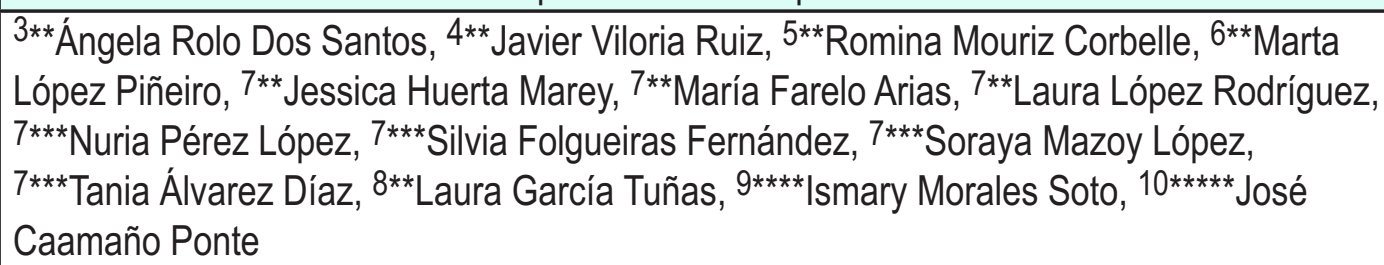 \\
\hline \begin{tabular}{|l}
${ }^{1}$ Geriatra, ${ }^{2}$ MIR Geriatría, ${ }^{3}$ Gerontóloga, ${ }^{4}$ Fisioterapeuta, ${ }^{5}$ Psicóloga, ${ }^{6}$ Trabajadora Social, \\
${ }^{7}$ Enfermera, ${ }^{8}$ Terapeuta Ocupacional, ${ }^{9}$ Médica, ${ }^{10}$ Dr. Medicina.
\end{tabular} \\
\hline 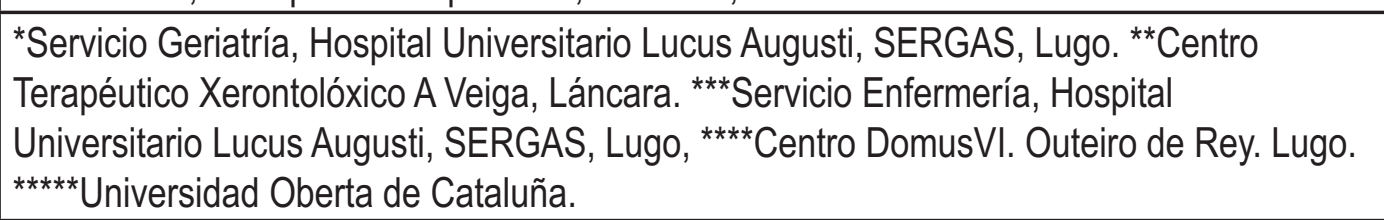 \\
\hline
\end{tabular}

